\title{
Micro structural and static structural analysis of LM6/B4C and LM6/B4C/GR hybrid aluminium metal matrix composites
}

\author{
M.H. Faisal ${ }^{1 *}$, S. Prabagaran ${ }^{2}$ \\ ${ }^{1}$ Research Scholar, Department of Mechanical Engineering, Karpagam Academy of Higher Education, Tamilnadu, India \\ ${ }^{2}$ Professor, Department of Mechanical Engineering, Karpagam Academy of Higher Education, Tamilnadu, India \\ *Corresponding author E-mail:faisalmh78@gmail.com
}

\begin{abstract}
This research work was performed to interpret the fabrication and mechanical characteristics of LM6/B4C and LM6/B4C/Gr aluminium matrix composites. The aluminium matrix composites were manufactured by reinforcing B4C particles with varying wt $\%$ of $3,5,7$ using stir casting technique. LM6/B4C 7\% composite was made hybrid by adding $2 \%$ Graphite into it. The presence of graphite in such composites provide the self-lubricating effect, replacing conventional sliding contacts (bearings, sheaves, pistons, pulleys) with them. This also helps to reduce the lubricating oil and fuel consumption along with environmental benefits reducing energy wastage in industrial and automotive components. The properties of the composites were collated with the base alloy to analyse the enhancement in mechanical characteristics that had been transmitted by the reinforcement particles to the composites. The specimen microstructure was inspected using an optical microscope to ensure the uniform distribution of reinforcement particles in the matrix. The piston was modelled in CREO and using ANSYS 14.5 workbench static structural analysis of LM6 alloy, LM6/B4C composite and LM6/B4C/Gr hybrid aluminium composites are executed. Compared to LM6 alloy, better static structural properties were obtained in composites and hybrid composite.
\end{abstract}

Keywords: LM6, hybrid aluminium matrix composite, boron carbide, graphite.

\section{Introduction}

Nowadays industrial areas such as defence, aerospace, consumer and automotive industries seeks advantages of transpiring metal matrix composites. Due to attractive material properties such as simpler fabricability, less density and better engineering characteristics, aluminium alloys are selected as matrix material. Better wear resistance, good specific stiffness, and lower coefficient of thermal expansion are some profits of aluminium metal matrix composites (AMCs) compared to Matrix materials. Such composites are also mentioned as light metal matrix composites in a lot of research works. Massive evolution in the advancement of light metal matrix composites have been attained in contemporary years so that they could be imported to the most crucial areas. Aluminium Metal Matrix Composites are the excellent substances in the industrial world by the virtue of their enhanced mechanical characteristics. Hence they are applied extensively in areas such as marine, automobiles and aerospace etc [1].Tough ceramic flecks like $\mathrm{SiC}, \mathrm{Al}_{2} \mathrm{O}_{3}$, and $\mathrm{B}_{4} \mathrm{C}$ etc can be used to strengthen the aluminium matrix. At the modern times also aluminium alloys are the matter of fervent researchers, as their inferior density provides extra significances in various areas. For producing wear resistance components these alloys can be used for replacing conventional cast iron and bronze materials. Compared to alloys, such particle reinforced MMCs produced by traditional methods yields characteristics improvement. Various engineering areas comprising transport and construction which requires excellent mechanical characteristics such as hardness, tensile strength etc uses $6061 \mathrm{Al}$ [2]. Compared to the analogous unreinforced alloy, boron carbide particulate reinforced aluminium composites retains an ideal consolidation of greater elastic modulus, high specific strength, excellent thermal stability and better wear resistance. Due to the greater expense of $\mathrm{B}_{4} \mathrm{C}$ and its poor wetting, a bounded research work has been expressed on aluminium matrix composites reinforced with boron carbide. This Boron carbide is a tough material possessing superior thermal and chemical stability, greater hardness $(\mathrm{HV}=30 \mathrm{Gpa})$, and less density $(2.52 \mathrm{~g} / \mathrm{cm} 3)$ and it is employed for producing armour tank, bullet proof vests etc. So, aluminium/boron carbide composites have secured more interest with cheaper stir casting technique [3].The manufacturing methods are accessible in liquid and solid state techniques and spray deposition process. However, all techniques have their distinctive manufacturing paths. Among these, liquid state techniques mainly stir casting technique has obviously a budgetary and has a countless range of combination and manufacturing methods. Since there is a thorough stirring operation, stir casting attains excellent bonding between matrix and reinforcing material. The major problem in the production is the complication to attain the better wettability, similitude of the particle distribution, minimised surface chemical reactions and porosity [4].Aluminium alloys are mainly utilised as a major matrix material in composites. The larger Al alloy usage is imposed by a very enticing amalgam of properties, added with the simplicity with which they may be fabricated in a huge diversity of patterns and shapes. The LM6 alloy is employed in aerospace, automobile and marine applications. The major limitation of such substance is that they show lower tribological characteristics. So, the ambition of the engineering field is to create an advanced material with excellent tribological properties and high wear resistance, without enough negotiation on the strength/weight ratio guided to the evolution of metal matrix composites [5]. 


\section{Materials and methodology}

\subsection{LM6}

LM6 aluminium alloy is generally employed for producing sliding contacts such as pistons, bearings, sheaves, pulleys etc. Important properties like superior machinability, excellent wear resistance and high temperature properties make LM6 ideal for our study.

Table 1: Elemental Composition of LM6

\begin{tabular}{|l|l|l|l|l|l|l|l|l|}
\hline ELEMENT & $\mathrm{Mg}$ & $\mathrm{Mn}$ & $\mathrm{Si}$ & $\mathrm{Fe}$ & $\mathrm{Ni}$ & $\mathrm{Zn}$ & $\mathrm{Ti}$ & $\mathrm{Al}$ \\
\hline WT\% & 0.01 & 0.3 & 10 & 0.4 & 0.05 & 0.08 & 0.02 & $\mathrm{Bal}$ \\
\hline
\end{tabular}

Table 2: Mechanical Properties of LM6

\begin{tabular}{|l|l|}
\hline PROPERTIES & VALUES \\
\hline Density $(\mathrm{kg} / \mathrm{m} 3)$ & 2680 \\
\hline Tensile strength $(\mathrm{Mpa})$ & $160-190$ \\
\hline Melting point $\left({ }^{\circ} \mathrm{C}\right)$ & 695 \\
\hline Poison's ratio & 0.33 \\
\hline Young's modulus (Gpa) & 71 \\
\hline
\end{tabular}

\subsection{Boron carbide}

The third-hardest substance next to diamond and boron nitride being Boron Carbide. It is chemically inert in nature. It also has better properties compared to alumina and silicon carbide. One of the main advantages is that it has good atomic bonding with the matrix material. Other important properties are good hardness, elastic modulus, stability at elevated temperature, excellent electrical as well as thermal properties etc.

Table 3: Mechanical Properties of Boron Carbide

\begin{tabular}{|l|l|}
\hline PROPERTIES & VALUES \\
\hline Density $(\mathrm{kg} / \mathrm{m} 3)$ & 2550 \\
\hline Tensile strength $(\mathrm{Mpa})$ & 500 \\
\hline Melting point $\left({ }^{\circ} \mathrm{C}\right)$ & 3500 \\
\hline Poison's ratio & 0.17 \\
\hline Young's modulus $(\mathrm{Gpa})$ & 460 \\
\hline
\end{tabular}

\subsection{Graphite}

It is an imperative opaque material commonly used as a solid lubricant. It can be distinguished by its black colour. One of its extensive feature includes its ability to exhibit both metals as well as non-metal properties. Major properties like good electrical/ thermal conductivity, inertness \& flexibility and refractive feature make it suitable for various types of equipment like piston rings, vanes, thrust bearings and journal bearings.

Table 4: Mechanical Properties of Graphite

\begin{tabular}{|l|l|}
\hline PROPERTIES & VALUES \\
\hline Density (kg/m3) & 1950 \\
\hline Tensile strength (Mpa) & 76 \\
\hline Melting point $\left({ }^{\circ} \mathrm{C}\right)$ & 3800 \\
\hline Poison's ratio & 0.21 \\
\hline Young's modulus (Gpa) & 12 \\
\hline
\end{tabular}

\subsection{Stir casting}

The fabrication of metal matrix composite employed in this research was performed by stir casting technique for which a stir casting equipment, comprising of a stirrer assembly and an Induction Furnace was employed to manufacture the composite. The stirrer unit is attached to a vertical fluctuating speed motor using a steel shaft. The speed selected was $400 \mathrm{rpm}$. In the core of furnace, graphite container of $0.5 \mathrm{Kg}$ was secured [6]. In the induction furnace, LM6 alloy was melted at $750^{\circ} \mathrm{C}$. Preheating of reinforcements ( $\mathrm{B}_{4} \mathrm{C}$ and Graphite) was performed for one hour at $350^{\circ} \mathrm{C}$ to ddive away humidity and gases from the reinforcement surfaces. The velocity of the stirrer was slowly increased to 400 rpm and the preheated particles were infused into the molten metal matrix. For ensuring excellent mixing of particles with the matrix, the stirring process was maintained for 6 minutes. Up to 30 seconds, the melt was retained in the crucible and then it was poured into the die [6]. Three samples of boron carbide 3\%, 5\% and $7 \%$ were made and in the last sample(7\%), $2 \%$ graphite is added.

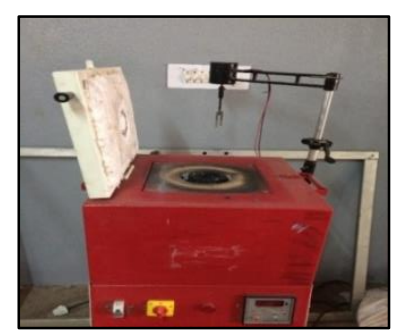

Fig. 1: Stir casting equipment

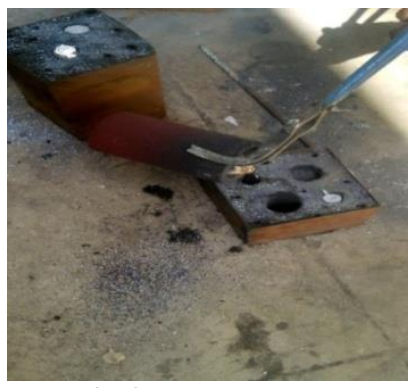

Fig. 2: Casting process

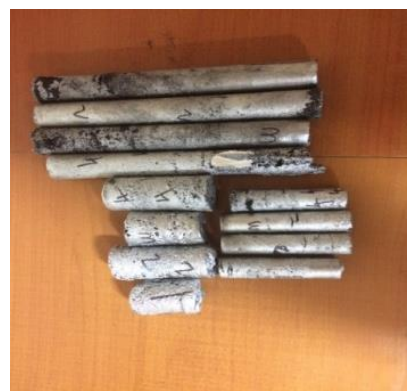

Fig. 3: Casted specimens

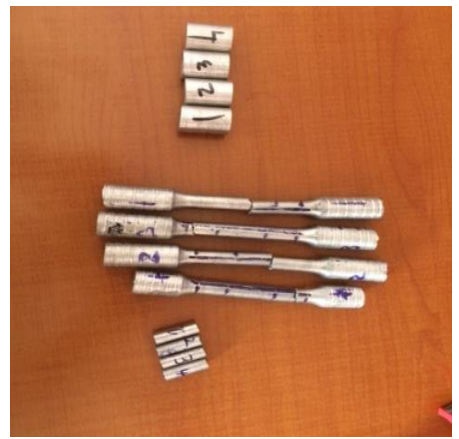

Fig. 4: Test specimens

\subsection{Microstructural analysis}

The Metallography deals with the investigation of the metallic structure which embraces the methods employed to develop samples for inspection, inspecting the sample and analysing the structures. Surface preparation is the dominant part of metallography which includes sample selection, sectioning, grinding, polishing, and etching to develop a mirror finish flat specimen. In the polished condition, attributes like porosity and inclusions can be simply perceived. Usually, surfaces are etched to obtain the microstructure. Etching is a restrained corrosion mechanism deriving from the electrolytic process between surfaces of discrete potential which perceives the microstructure by discriminatory structural dissolution. Then with the aid of 
optical and electron microscopes samples are examined Metallographic sample images are given below

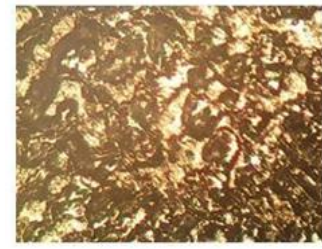

Mag: 100X

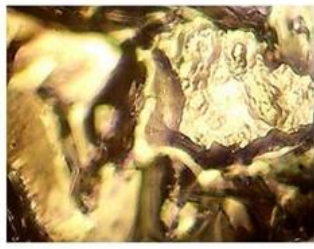

Mag: 500X
Fig. 5: Sample 1 ( $\left.\mathrm{LM} 13 / \mathrm{B}_{4} \mathrm{C} 3 \%\right)$

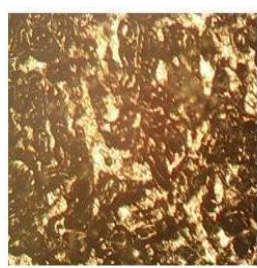

Mag: $100 \mathrm{X}$

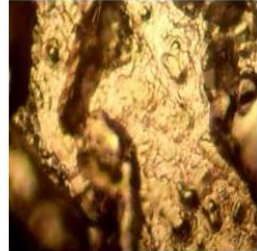

Mag: 500X
Fig. 6: Sample 2 ( $\mathrm{LM} 6 / \mathrm{B}_{4} \mathrm{C} 5 \%$ )

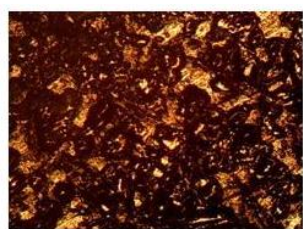

Mag: 100X

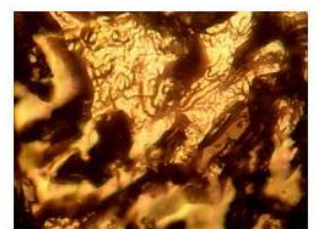

Mag: 500X
Fig. 7: Sample 3 ( $\mathrm{LM} 6 / \mathrm{B}_{4} \mathrm{C} 7 \% / \mathrm{Gr} 2 \%$ )

\subsection{Finite element analysis}

In order to validate and before going for concluding the research findings, ANSYS - a proven analysis software is used. This is a package in which researcher can put torques, pressures, forces etc on the developed models and notice the stresses formed. The widest and thorough advanced engineering simulation suite is developed on the ANSYS Workbench. An ingenious program illustrative perspective resides together the whole simulation operation, leading the researcher through difficult multiphase analysis with multidirectional CAD network, a computerised research level program, unified optimisation tools and superior criterion management which convey productivity, sanctioning simulation enabled model development

\section{Results and discussion}

The test results are explained in the following sections.

\subsection{Microstructural analysis}

By performing the metallographic analysis of the developed samples uniform distribution of reinforcements is observed. The prime reason for the homogeneity is the better wettability of the boron carbide particles leading the evolution of oxide layer on the B4C particles. Such phenomena help to reduce the porosity level and to achieve excellent matrix (LM6) and reinforcement bonding.

\subsection{Static structural analysis}

a) LM6

The maximum von-mises stress developed in the piston as a result of the pressure acting on the piston top face is $151.72 \mathrm{MPa}$ which is represented in figure 9. Figure 10 and 11 shows the total deformation and equivalent elastic strain which is 111 microns and 0.0017731 respectively.

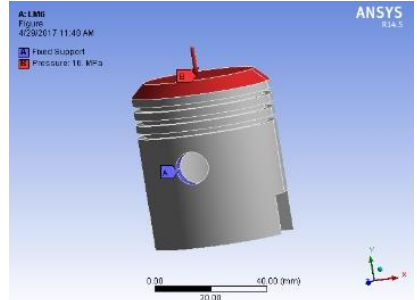

Fig. 8: Fixed support model for LM6

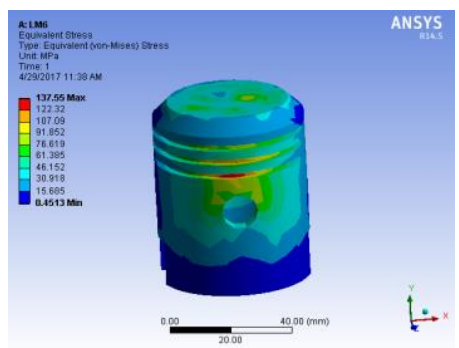

Fig. 9: Equivalent stress for LM6

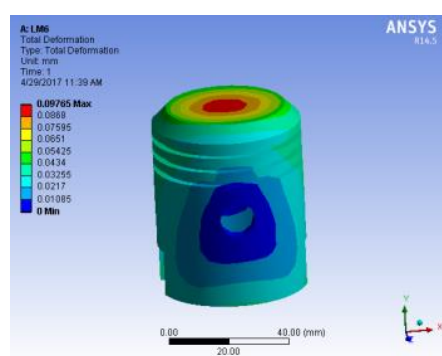

Fig. 10: Total deformation for LM6

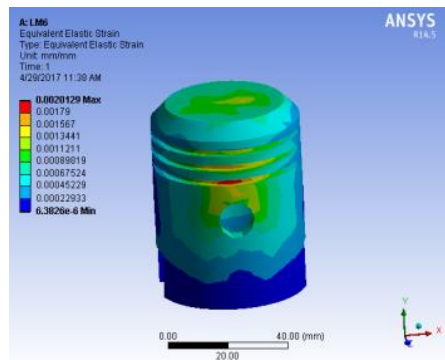

Fig. 11: Equivalent elastic strain for LM6

b) $\mathrm{LM} 6 / \mathrm{B}_{4} \mathrm{C} 3 \%$ aluminium composite

The maximum von-mises stress developed in the piston as a result of the pressure acting on the piston top face is $151.72 \mathrm{MPa}$ which is represented in figure 13. Figure 14 and 15 shows the total deformation and equivalent elastic strain which is 111 microns and 0.0017731 respectively.

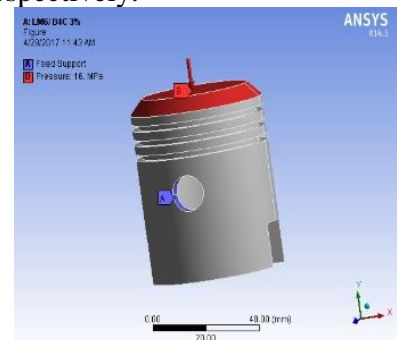

Fig. 12: Fixed support model for $\mathrm{LM} 6 / \mathrm{B}_{4} \mathrm{C} 3 \%$ 


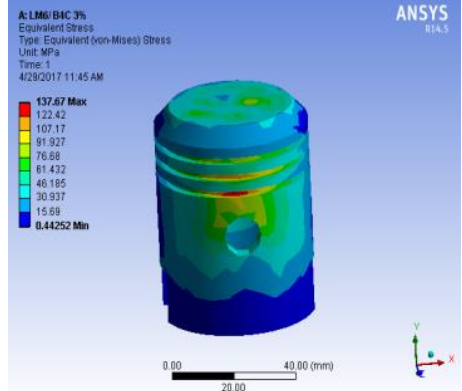

Fig. 13: Equivalent stress for $\mathrm{LM} 6 / \mathrm{B}_{4} \mathrm{C} 3 \%$

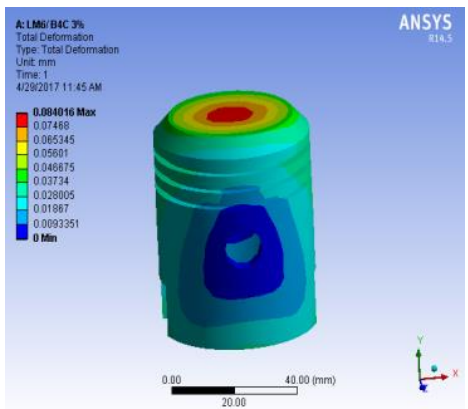

Fig. 14: Total deformation for $\mathrm{LM} 6 / \mathrm{B}_{4} \mathrm{C} 3 \%$

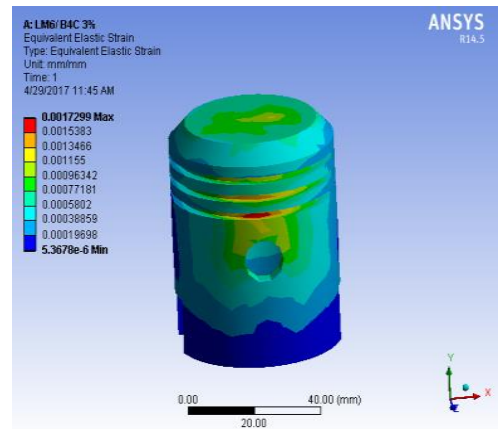

Fig. 15: Equivalent elastic strain for $\mathrm{LM} 6 / \mathrm{B}_{4} \mathrm{C} 3 \%$

c) $\mathrm{LM} 6 / \mathrm{B}_{4} \mathrm{C} 5 \%$ aluminium composite

The maximum von-mises stress developed in the piston as a result of the pressure acting on the piston top face is $151.72 \mathrm{MPa}$ which is represented in figure 17. Figure 18 and 19 shows the total deformation and equivalent elastic strain which is 111 microns and 0.0017731 respectively.

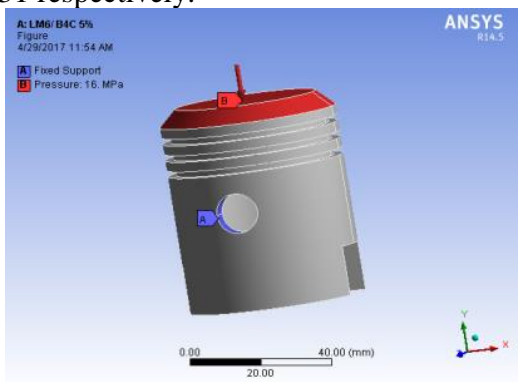

Fig. 16: Fixed support model for $\mathrm{LM} 6 / \mathrm{B}_{4} \mathrm{C} 5 \%$

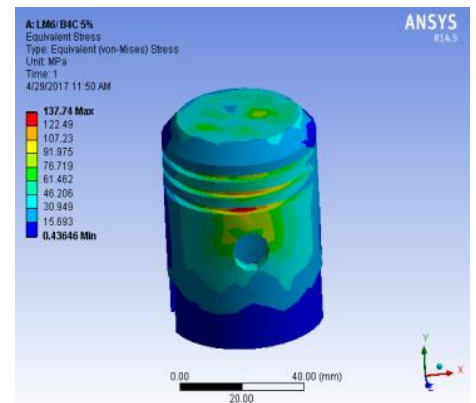

Fig. 17: Equivalent stress for $\mathrm{LM} 6 / \mathrm{B}_{4} \mathrm{C} 5 \%$

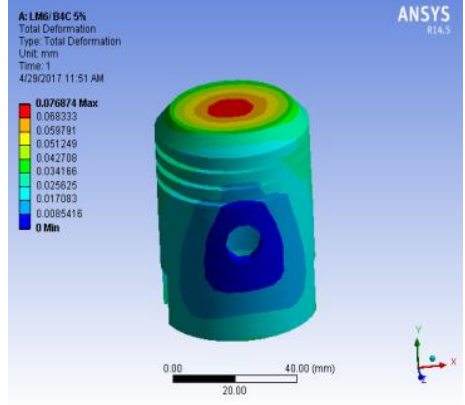

Fig. 18: Total deformation for $\mathrm{LM} 6 / \mathrm{B}_{4} \mathrm{C} 5 \%$

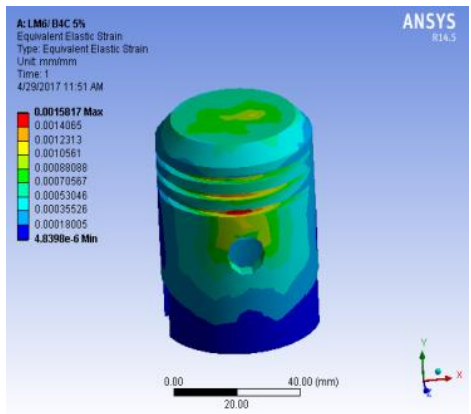

Fig. 19: Equivalent elastic strain for $\mathrm{LM} 6 / \mathrm{B}_{4} \mathrm{C} 5 \%$

d) $\mathrm{LM} 6 / \mathrm{B}_{4} \mathrm{C} 7 \% / \mathrm{Gr} 2 \%$ hybrid aluminium composite

The maximum von-mises stress developed in the piston as a result of the pressure acting on the piston top face is $151.72 \mathrm{MPa}$ which is represented in figure 21 . Figure 22 and 23 shows the total deformation and equivalent elastic strain which is 111 microns and 0.0017731 respectively.

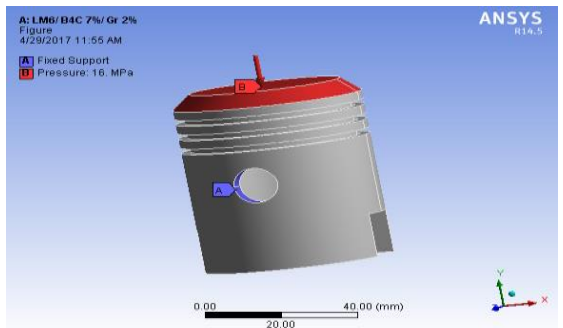

Fig. 20: Fixed support model for $\mathrm{LM} 6 / \mathrm{B}_{4} \mathrm{C} 7 \% / \mathrm{Gr} 2 \%$

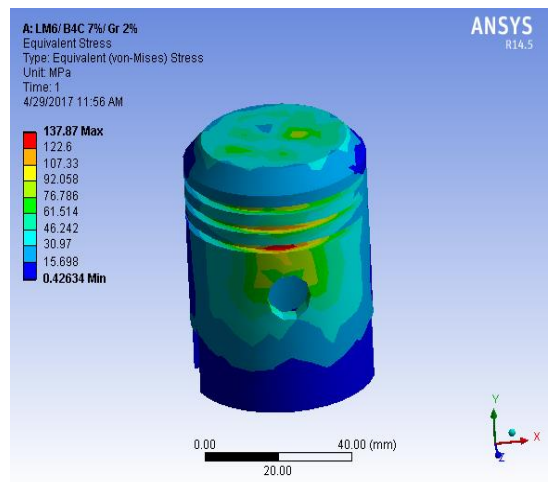

Fig. 21: Equivalent stress for $\mathrm{LM} 6 / \mathrm{B}_{4} \mathrm{C} 7 \% / \mathrm{Gr} 2 \%$ 


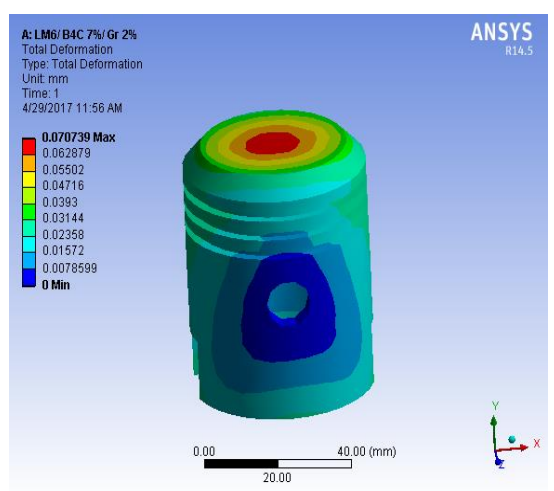

Fig. 22: Total deformation for $\mathrm{LM} 6 / \mathrm{B}_{4} \mathrm{C} 7 \% / \mathrm{Gr} 2 \%$

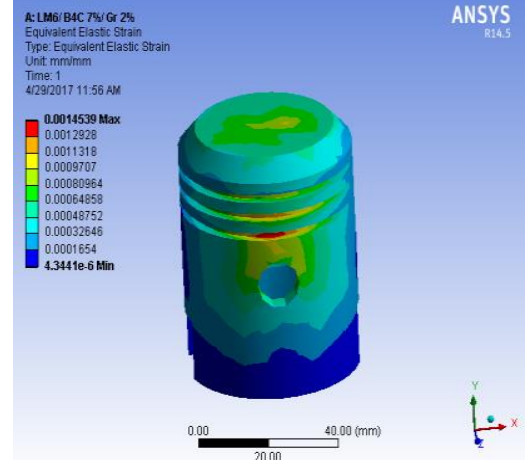

Fig. 23: Equivalent elastic strain for $\mathrm{LM} 6 / \mathrm{B}_{4} \mathrm{C} 7 \% / \mathrm{Gr} 2 \%$

\section{Comparison between alloy and composites}

Static structural properties obtained are shown in following table.

Table 5: Static structural results

\begin{tabular}{|l|l|l|l|}
\hline Properties & Equivalent Stress (MPa) & Total deformation $(\mathrm{mm})$ & Equivalent elastic strain \\
\hline LM6 & 137.55 & 0.09765 & 0.0020129 \\
\hline LM6/B 4 C 3\% & 137.67 & 0.084016 & 0.0017299 \\
\hline LM6/B H $_{4}$ C & 137.74 & 0.076874 & 0.0015817 \\
\hline LM6/B 4 C 7\%/Gr 2\% & 137.87 & 0.070739 & 0.0014539 \\
\hline
\end{tabular}

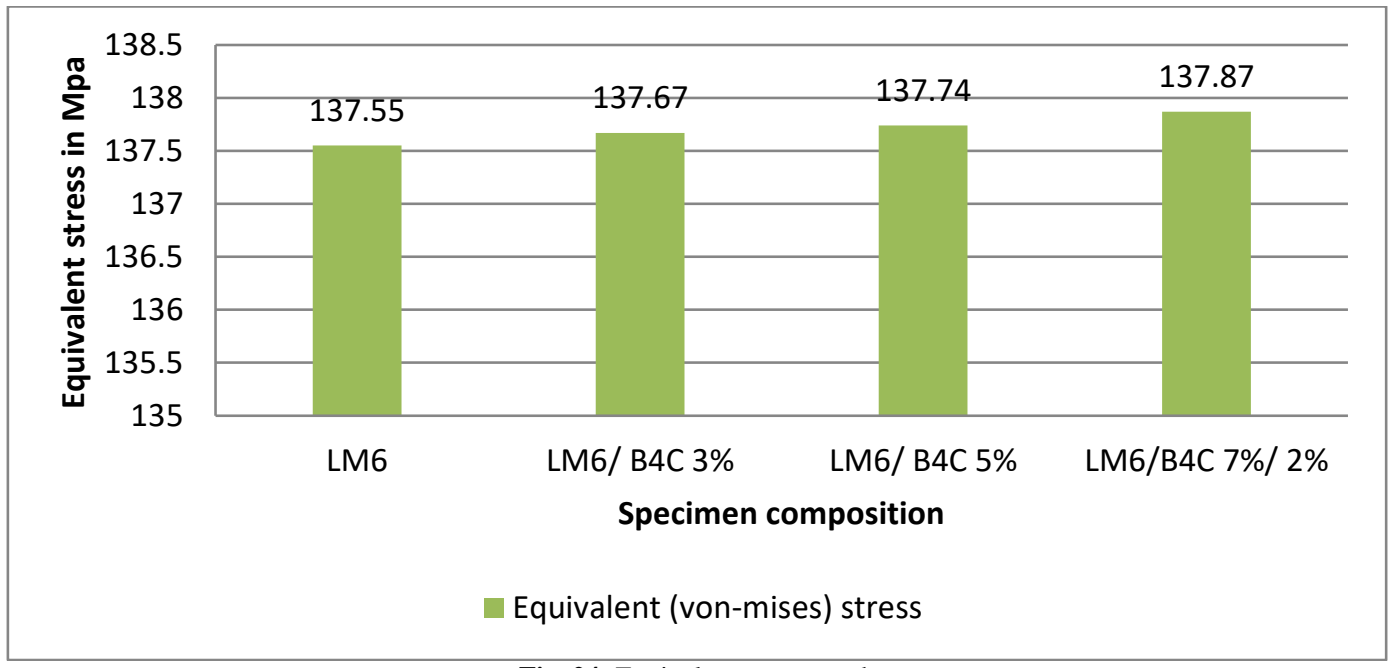

Fig. 24: Equivalent stress graph

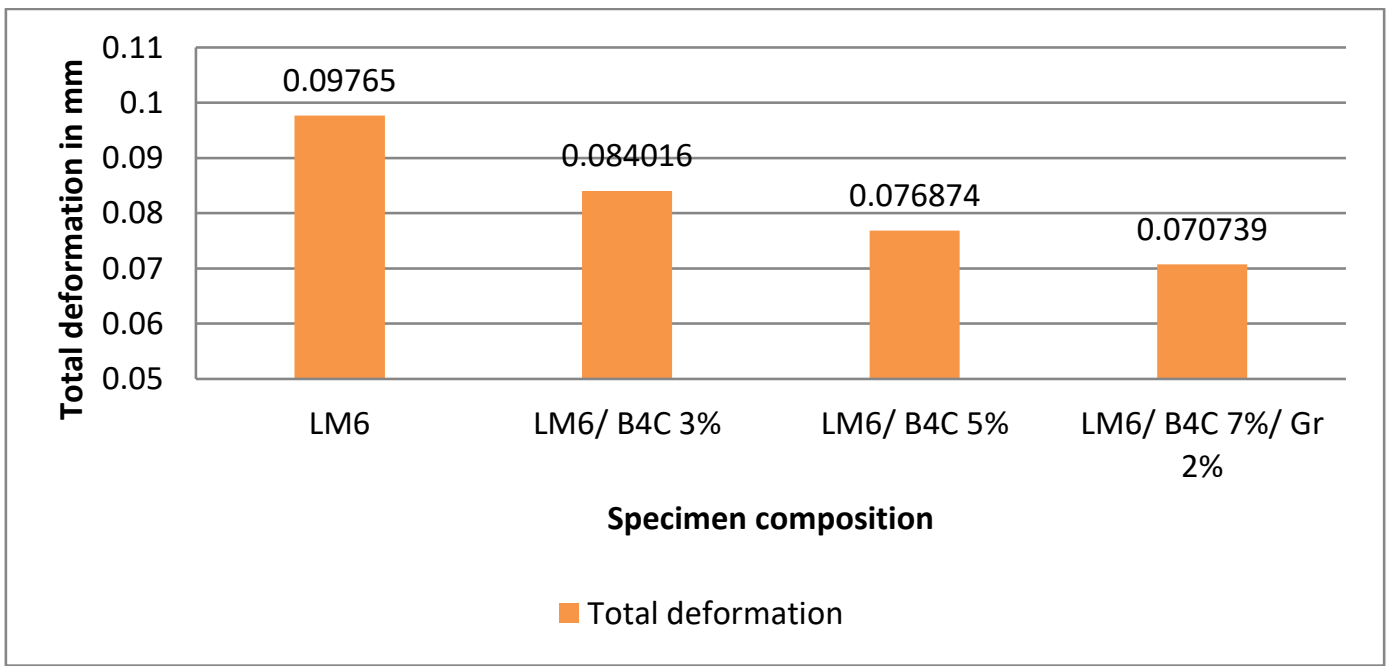

Fig. 25: Total deformation graph 


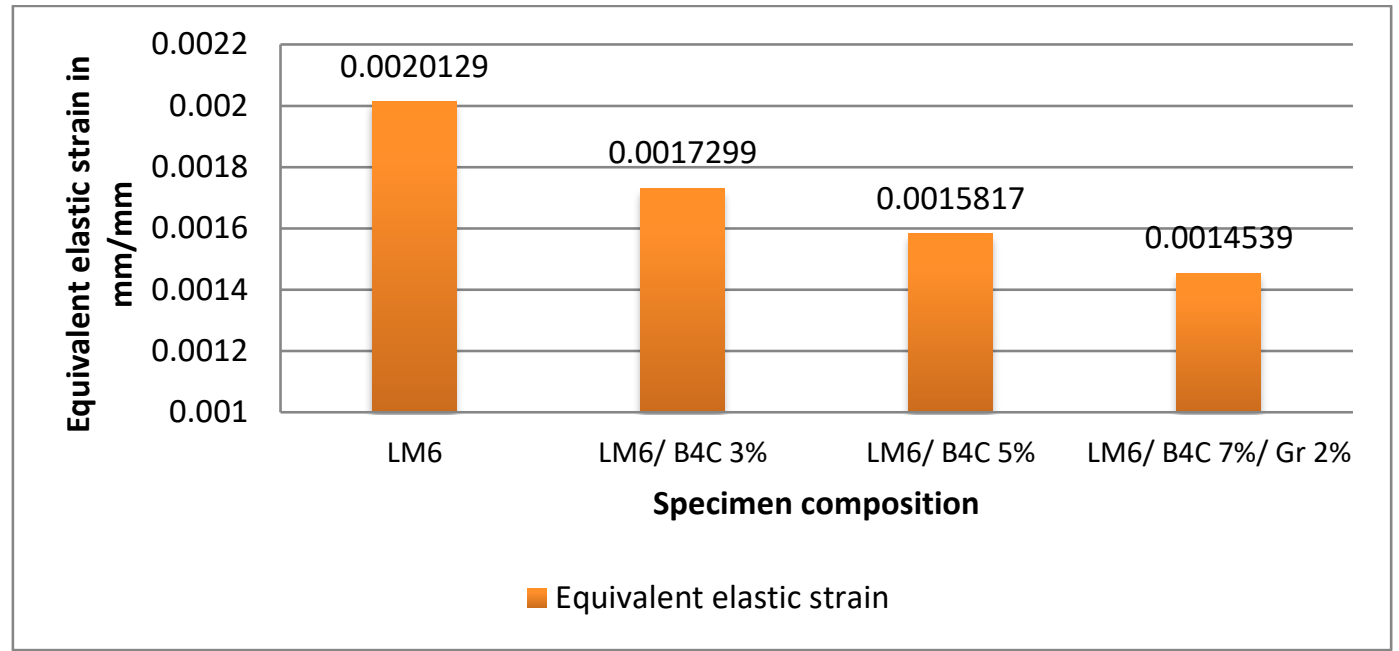

Fig. 26: Equivalent elastic strain graph

By analysing the obtained results we can see that as the volume of boron carbide particles increases, deformation of the material decreases. This is due to the excellent reinforcement properties exhibited by boron carbide. The LM6/B4C 7\%/Gr $2 \%$ hybrid aluminium composite sample also exhibit better mechanical properties than unreinforced alloy LM6. Similarly, the equivalent elastic strain was decreased associated with a small hike in von misses stresses.

\section{Conclusion}

Liquid metallurgy technique (stir casting) was employed to fabricate required sample specimens with uniform boron carbide and graphite (in 3rd sample) distribution. This also helped to reduce the expense of fabrication. Compared to the unreinforced LM6 alloy, LM6/B4C and LM6/B4C/Gr composites exhibited better mechanical properties. To create piston model, CREO was used and static structural analysis of composites as well as LM6 piston was performed using ANSYS (WORKBENCH 14.5). As the boron carbide percent increases, properties like deformation and the equivalent strain was increased associated with better von misses stress characteristics which show that composite materials exhibit better mechanical properties than unreinforced alloys. Most preferred composite is LM6/B4C/Gr which can be employed as a replacement to the conventional LM6 material used in sliding contacts to obtain better properties.

\section{References}

[1] Feng YC, Geng L, Zheng PQ, Zheng ZZ \& Wang GS, "Fabrication and characteristic of Al-based hybrid composite reinforced with tungsten oxide particle and aluminum borate whisker by squeeze casting”, Materials \& Design, Vol.29, (2008), pp.2023-2026.

[2] Mohanty RM, Balasubramanian K \& Seshadri SK, "Boron carbidereinforced alumnium 1100 matrix composites:fabrication and properties", Material Science Eng. A, Vol.498, (2008), pp.42-52.

[3] Kerti I \& Toptan F, "Microstructural variations in cast B4Creinforced aluminium matrix composites(AMCs)", Mater. Lett., Vol.62, (2008), pp.1215-8.

[4] Rabiei A, Vendra L \& Kishi T, "Fracture behavior of particle reinforced metal matrix composites", Science direct Composites: Part A, Vol.39, (2008), pp.294-300.

[5] Mahendra Boopathi M, Arulshri KP \& Iyandurai N, "Evaluation of Mechanical properties of Aluminium alloy 2024 reinforced with Silicon Carbide and Fly Ash hybrid metal matrix composites", American Journal of Applied Sciences, Vol.10, No.3, (2013), pp.219-229.

[6] Ravesh SK \& Garg TK, "Preparation \& Analysis for some mechanical property of Aluminium based metal matrix composite reinforced with $\mathrm{SiC} \&$ Fly Ash", International Journal of Engineering Research and Applications, Vol.2, No.6, (2012), pp727-731.
[7] Dolata-Grosz A, Dyzia M, Śleziona J \& Wieczorek J, "Composites Applied For Pistons", Archives of Foundry Engineering, Vol7, No.1,(2007), pp.37-40

[8] Surendar, A., Arun, M.’FPGA based multi-level architecture for next generation DNA sequencing",(2016) Biomedical Research (India), 2016, pp. S75-S79.

[9] Surendar, A., Arun, M., Basha, A.M.'Micro sequence identification of bioinformatics data using pattern mining techniques in FPGA hardware implementation",(2016) Asian Journal of Information Technology, 15 (1), pp. 76-81.

[10] Prabu, G., Surendar, A."Virus detection by using a pattern matching algorithm for network security",(2015) International Journal of Applied Engineering Research, 10 (10), pp. 9565-9569.

[11] Prabagaran S, Chandramohan G \& Shanmughasundaram P, "Influence of Graphite on the hardness and wear behavior of AA6061-B4C Composite", Materiali in tehnologije/Materials and technology, Vol.48, (2014), pp.661-667.

[12] Rama Rao S \& Padmanabhan G, "Fabrication and Mechanical Properties of Aluminium-Boron Carbide Composites", International Journal of Materials and Biomaterials Applications, Vol.2, No.3, (2012), pp.15-18. 